\title{
Efeito da adição de polpa, carboximetilcelulose e goma arábica nas características sensoriais e aceitação de preparados em pó para refresco sabor laranja
}

\author{
Effect of adding pulp, carboxymethyl cellulose and arabic gum to sensory \\ characteristics and acceptance of powdered orange-flavored refreshments
}

\author{
Valentina de Fátima CALEGUER ${ }^{1}$, Marta de Toledo BENASSI ${ }^{1 *}$
}

\begin{abstract}
Resumo
O trabalho teve como objetivo avaliar o efeito sensorial da adição de polpa, carboximetilcelulose (CMC) e goma arábica (fibra) nos atributos e aceitação de refrescos de laranja. Utilizou-se uma amostra padrão e outras formuladas com polpa, CMC, fibra e todos os ingredientes. Foram realizadas análises físico-químicas $(\mathrm{pH}$, acidez titulável, sólidos solúveis, vitamina $\mathrm{C}$, cor e turbidez), e as amostras também foram caracterizadas pela técnica de Perfil Livre. Na análise descritiva utilizou-se 14 provadores e, para a avaliação dos resultados foi empregada a Análise Procrustes Generalizada. As amostras caracterizadas como diferentes (padrão, CMC, fibra) foram submetidas a teste de aceitação. Os refrescos foram caracterizados e separados com base em atributos de aparência (cor laranja e turbidez), aroma (adocicado e laranja), sabor (doce, laranja e ácido) e textura (viscosidade). O padrão e a amostra com polpa, que não foram diferenciadas sensorialmente, apresentaram menor intensidade de cor laranja e turbidez, e foram consideradas menos encorpadas e mais ácidas. As amostras com CMC e fibra se diferenciaram do padrão e apresentaram comportamento intermediário. A formulação com todos os ingredientes apresentou características opostas: maior intensidade de cor e turbidez, mais encorpada e menos ácida. As amostras com CMC e fibra foram mais aceitas que o padrão.

Palavras-chave: perfil livre; consumidor; cor; turbidez; acidez.
\end{abstract}

\begin{abstract}
The aim of this work was to evaluate the sensory effect of adding pulp, carboxymethyl cellulose (CMC) and arabic gum (fiber) to characteristics and acceptance of powdered orange flavored soft drinks. A standard sample and another formulated with pulp, CMC, fiber with all the ingredients were used. Physicochemical analyses ( $\mathrm{pH}$, titratable acidity, soluble solids, vitamin $\mathrm{C}$, color and turbidity) were applied and samples were characterized by Free-Choice Profiling. Fourteen panelists were used in the descriptive analysis and the Generalized Procrustes Analysis was applied to evaluate the results. The formulations characterized as different (standard, CMC, fiber) underwent an acceptance test. Samples were characterized and separated based on attributes such as appearance (orange color, cloudiness), aroma (sweet, orangelike), taste (sweet, orange-like, acid) and texture (viscosity). The standard and the pulp formulated ones, which were not differentiated by descriptive, were characterized for less intense orange color and cloudiness, and were considered less viscous and more acid. The CMC and fiber samples were differentiated from the standard and featured intermediate characteristics. The formulation with all ingredients presented opposite characteristics: higher color intensity, cloudiness and viscosity, as well as less acid. Samples with CMC and fiber were more accepted than the standard.
\end{abstract}

Keywords: free-choice profiling; consumers; color; cloudiness; acidity.

\section{Introdução}

Os refrescos em pó, embalados em envelopes, estão presentes em escolas, restaurantes, indústrias e supermercados, entrando no espaço da comodidade, no lugar dos sucos naturais. A partir do final da década de 1990, a formulação dos preparados em pó para refresco foi se modificando para tornarse mais atraente ao consumidor com a introdução, além dos ingredientes usuais, de polpa e/ou suco desidratado de frutas e fibras solúveis na composição dos produtos ${ }^{7,8,22,23}$.

A polpa de fruta é definida como "o produto não fermentado, não concentrado, obtido de frutas, por processos tecnológicos adequados com um teor de sólidos em suspensão mínimo"3.

A incorporação de fibra em um alimento modifica sua aparência, textura e estabilidade. Considerando-se o interesse

Recebido para publicação em 10/4/2006

Aceito para publicação em 23/4/2007 (001731)

Departamento de Tecnologia de Alimentos e Medicamentos,

Universidade Estadual de Londrina - UEL,

CP 6001, CEP 86051-990, Londrina - PR, Brasil,

E-mail:martatb@uel.br

*A quem a correspondência deve ser enviada do consumidor de incluir fibras na alimentação, em complemento a fontes como cereais integrais, frutas e vegetais, existe a opção de fortificação de produtos tradicionais. Em bebidas, ingredientes com alto teor de fibras, mas baixo impacto na viscosidade, são os mais utilizados ${ }^{13,25}$.

A carboximetilcelulose (CMC) pode ser encontrada sob várias apresentações, dependendo do tamanho de partículas, grau de substituição, viscosidade e características de hidratação, e apresenta estabilidade em $\mathrm{pH}$ ácido. Encontra-se freqüentemente presente na composição de preparados sólidos para refresco, como espessante, estabilizante e agente de corpo $^{18,25}$.

A goma acácia, também denominada arábica, dissolve-se facilmente em água quente e origina soluções menos viscosas que a CMC, podendo ser utilizada em concentrações de até $10 \%$ como fibra solúvel, sem modificar a textura ${ }^{25}$. Atualmente no Brasil, os preparados para refresco que mencionam presença de fibra são formulados empregando-se goma acácia ${ }^{6}$.

A avaliação sensorial permite tanto a identificação de pequenas diferenças entre produtos, quanto a definição de seus atributos sensoriais, utilizando técnicas descritivas. Permite ainda, avaliar a aceitabilidade do produto ${ }^{15}$. 
O Perfil Livre é uma técnica de análise descritiva baseada no princípio de que as pessoas percebem as mesmas características no produto, mesmo que se expressem de forma diferenciada. Cada provador caracteriza as amostras utilizando um perfil individual, dispensando treinamento. Os resultados são avaliados pela Análise Procrustes Generalizada (GPA), que elimina variações na descrição das amostras, permitindo detectar provadores com diferença na percepção e/ou falta de repetibilidade $^{2,16}$.

Os fabricantes, usualmente, atribuem às modificações nas formulações tradicionais a melhora na aceitação e o aumento no consumo dos preparados sólidos nos últimos anos ${ }^{7,8}$, no entanto, não existem trabalhos na literatura que avaliem o impacto sensorial dessas alterações.

Em trabalho anterior, estudando-se produtos de mercado com diferentes composições, observou-se que a turbidez influenciava na aceitação de refrescos sabor laranja comerciais. Também foi relatado, que a descrição no rótulo do produto da adição de polpa ou fibra tinha impacto positivo na intenção de compra do consumidor de refrescos em pó ${ }^{4}$.

Dessa forma, a partir de um preparado sólido para refresco comercial, que não continha na composição polpa/suco e hidrocolóides, foram formulados produtos com a adição desses ingredientes nas concentrações usualmente empregadas nos produtos de mercado. O objetivo do trabalho foi avaliar o efeito sensorial da adição de suco, goma arábica e carboximetilcelulose nos atributos sensoriais e físico-químicos e a aceitação dos preparados em pó para refrescos sabor laranja.

\section{Material e métodos}

\subsection{Amostras}

Foi utilizada como amostra padrão, um produto comercial que teve aceitação (nota média 5,6, em escala hedônica de 9 pontos) em um trabalho realizado anteriormente 4 . Para essa amostra, que não continha polpa/suco e hidrocolóides, foram feitas modificações na formulação. Segundo o rótulo, a amostra padrão apresentava na composição: ácidos fumárico e cítrico, citrato de sódio, fosfato tricálcico, dioctil sulfossucinato de sódio, ácido ascórbico, açúcar, dióxido de titânio, aroma natural de laranja, corantes amarelo-crepúsculo e amarelotartrazina. Como ingredientes adicionais foram utilizados: suco desidratado, gomas acácia e CMC.

A goma acácia FIBREGUM B IRX 61380, cedida pela empresa Colloüdes Naturels Brasil (CNI, São Paulo, Brasil), tinha como características: umidade $10 \%$, pureza superior a $90 \%, \mathrm{pH} 4,1$ a 5, tamanho de partícula $\leq 15 \%$ em 250 mesh, e viscosidade da solução 25\% de 60 a 130 MPa.s (em Brookfield 50 rpm).

Empregou-se CMC Cekol 30.000 (NOVIANT, Nijemenjen, Holanda) com pureza de 99,5\%, grau de substituição de 0,81, umidade $5,7 \%$ e viscosidade $1 \%$ de 2880 MPa.s.

Para produtos de laranja não existe disponibilidade de polpa, sendo empregado o suco de laranja desidratado por spray dryer. No entanto, como esse componente é mais usualmente citado como polpa nos rótulos das embalagens, essa denomina- ção será a empregada no trabalho. Utilizou-se suco desidratado (Anidro do Brasil Desidratação, Botucatu, Brasil) com umidade de $3,4 \%$ e que empregava maltodextrina como excipiente.

$\mathrm{Na}$ preparação dos formulados, adicionou-se à amostra padrão suco e hidrocolóides nas concentrações usualmente empregadas. Para o preparo do formulado com suco seguiu-se o descrito nos rótulos dos produtos de mercado. Para CMC e goma acácia, os teores utilizados foram sugeridos pelos fabricantes ${ }^{6,17}$.

Os produtos foram formulados conforme descrito abaixo:

- Polpa: adição ao padrão de $1 \%$ de suco desidratado, considerando-se o peso do preparado seco (50 g);

- Fibra: adição ao padrão de 0,5\% de goma acácia, considerando-se a pureza de $85 \%$ para a goma e o volume de suco preparado;

- CMC: adição ao padrão de 0,1\% de carboximetilcelulose, considerando-se o volume de suco preparado; e

- Tudo: adição ao padrão dos ingredientes (suco, goma acácia e CMC) nas proporções descritas acima.

Para o preparo da amostra padrão, o refresco em pó foi misturado a $190 \mathrm{~g}$ de açúcar e depois dissolvido em $2 \mathrm{~L}$ de água, conforme especificação do fabricante. Na preparação dos formulados, os ingredientes foram primeiramente adicionados à mistura de açúcar e pó para refresco e depois dissolvidos. Os refrescos foram mantidos sob refrigeração a $7 \pm 2{ }^{\circ} \mathrm{C}$ até o momento da análise.

\subsection{Análises físico-químicas}

Para determinação do $\mathrm{pH}$, as amostras foram analisadas diretamente utilizando-se um pHmetro HANNA. Para avaliação da acidez total titulável, foi feita a titulação com a solução de hidróxido de potássio $0,1 \mathrm{~N}$ e a acidez foi expressa em gramas de ácido cítrico/100 mL da amostra ${ }^{5,10}$.

A porcentagem de sólidos solúveis totais foi determinada utilizando-se um refratômetro LEICA. As medidas foram expressas em graus ${ }^{\circ}$ Brix e as leituras foram corrigidas em função da temperatura ${ }^{10}$.

Para determinação do teor de ácido ascórbico, foi utilizado o método titulométrico oficial da $\mathrm{AOAC}^{1}$. As amostras, diluídas com a solução de extração, ácido oxálico $2 \%{ }^{2}$, foram tituladas, sendo o ponto de viragem determinado visualmente.

Para avaliação da intensidade de cor e turbidez empregou-se um espectrofotômetro UV-Visível GBC Cintra 20. Os espectros foram previamente avaliados na faixa de 190 a $650 \mathrm{~nm}$. A turbidez foi determinada pela leitura de absorvância a $600 \mathrm{~nm}^{12}$. Para avaliação da intensidade de cor, dos valores de absorvância a 450 nm (máximo de intensidade nos espectros) foi subtraída a leitura a $600 \mathrm{~nm}$ para eliminar a interferência da turbidez.

As análises foram realizadas em duplicata, empregandose delineamento inteiramente ao acaso. Os resultados foram submetidos à análise de variância e teste de médias (Tukey, $\mathrm{p} \leq 0,05$ ), utilizando o programa STATÍSTICA versão $6.0^{24}$. 


\subsection{Análise sensorial}

\section{Caracterização dos provadores e condições dos testes}

Para caracterização dos provadores na aceitação, foi entregue um questionário de coleta de dados de faixa etária, sexo, escolaridade e hábitos de consumo referentes às amostras em questão. Para a análise descritiva, foi ainda perguntado aos provadores sobre experiência prévia em testes sensoriais.

Todos os testes foram realizados em laboratório de Análise Sensorial, em cabines individuais e luz branca. As amostras, em torno de $50 \mathrm{~mL}$, foram servidas à temperatura de refrigeração, em recipiente de plástico transparente codificado com três dígitos e com ordem de apresentação aleatorizada para cada sessão. As amostras foram servidas de forma seqüencial, e entre as provas foi oferecida água.

\section{Perfil livre}

Participaram da análise descritiva 14 provadores: alunos, professores e funcionários da Universidade Estadual de Londrina. Antes do início dos testes, foi dada uma explicação aos provadores sobre o método do Perfil Livre. Os provadores foram ainda instruídos sobre como observar os atributos de aparência, aroma, sabor e textura.

Para o levantamento de atributos, foram realizadas duas sessões aplicando o método de rede $^{14}$. Em cada sessão foi apresentado um par de amostras, e solicitado aos provadores que anotassem as similaridades e diferenças em cada par. Após estas sessões, foi realizada uma discussão individual com o provador e foram montadas uma ficha de avaliação das amostras e uma lista de definições dos atributos específicos para cada provador. Para a quantificação foi utilizada, para cada atributo, uma escala de intensidade não-estruturada de $9 \mathrm{~cm}$, ancorada com termos verbais de intensidade nos extremos (Figura 1).

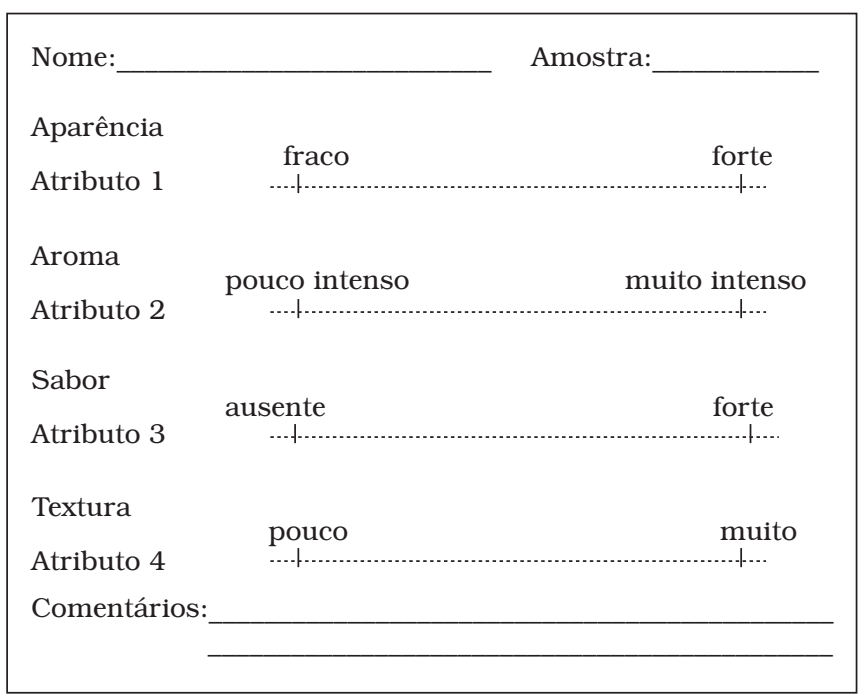

Figura 1. Ficha-modelo para avaliação de refresco sabor laranja por Perfil Livre.
Para avaliar a adequação das fichas e glossários foi empregada uma sessão simulando a apresentação para o teste descritivo. Os provadores avaliaram três amostras e puderam alterar as fichas quando necessário, retirando ou incluindo atributos, mudando os termos nos extremos das escalas e melhorando as definições no glossário.

Para avaliação dos refrescos, empregou-se um delineamento de blocos incompletos balanceados para cinco amostras (Tabela 1). O provador recebeu, junto com a ficha de avaliação, o seu glossário. Foram realizadas cinco sessões, com três provas por sessão, sendo que em cada sessão o mesmo bloco foi avaliado por todos os provadores. A ordem de apresentação foi aleatorizada dentro de cada sessão. Cada amostra foi apresentada ao provador num total de três vezes.

Tabela 1. Delineamento experimental utilizado no Perfil Livre.

\begin{tabular}{clll}
\hline Bloco & & Tratamento & \\
\hline$(1)$ & Padrão & Polpa & CMC \\
$(2)$ & Polpa & Fibra & Tudo \\
$(3)$ & Fibra & CMC & Padrão \\
$(4)$ & CMC & Tudo & polpa \\
$(5)$ & Tudo & Padrão & Fibra \\
\hline
\end{tabular}

Os dados do Perfil Livre foram analisados pela Análise Procrustes Generalizada, utilizando o programa Senstools versão 2.3.28 ${ }^{20}$. Os dados foram inseridos na forma de 14 matrizes (uma por provador) de quinze linhas (cinco amostras com três repetições) e o número de colunas variando de 5 a 11 (atributos).

\section{Teste de aceitação}

Foram utilizadas no teste de aceitação a amostra padrão e as amostras formuladas, que se mostraram diferenciadas na análise descritiva.

Participaram do teste de aceitação 118 possíveis consumidores, com idades variáveis, funcionários da indústria "Dori - Indústria e Comércio de Produtos Alimentícios Ltda" (Rolândia - PR) e alunos e funcionários da Universidade Estadual de Londrina.

Cada provador avaliou três amostras em uma sessão. Utilizou-se escala hedônica semi-estruturada de nove pontos, ancorada com termos verbais nos extremos e no meio, solicitando-se que fossem citadas características mais ou menos gostadas por amostra.

Os resultados foram submetidos à análise de variância, considerando-se como causa de variação as amostras e provadores, e teste de médias (Tukey, $\mathrm{p} \leq 0,05$ ), utilizando-se o programa STATISTICA versão $6.0^{24}$.

\section{Resultados e discussão}

\subsection{Perfil livre}

\section{Caracterização dos provadores}

A equipe da análise descritiva foi composta por 14 provadores: 4 homens e 10 mulheres. Os participantes eram jovens: 
$36 \%$ dos provadores estavam na faixa etária entre 15 a 25 anos e $43 \%$ entre 25 a 35 anos.

A equipe caracterizava-se pela alta escolaridade $(86 \%$ possuíam o $3^{\circ}$ grau completo) e experiência prévia com análise sensorial: $92 \%$ já haviam participado de teste de aceitação/ preferência, 31\% de testes discriminativos, e 17\% de análises descritivas. Os provadores gostavam do produto refresco de fruta (93\%) e do sabor laranja (92\%).

A equipe apresentava também familiaridade com o produto. A maioria dos provadores (64\%) relatava consumir refrescos em geral freqüentemente (algumas vezes por semana) e estava habituada ao consumo de preparados em pó comerciais (57\%) (Figura 2).

É interessante observar, que das pessoas que consumiam preparados em pó, apenas 33\% diziam comprar sempre o mesmo tipo de sabor e/ou marca. Quanto ao consumo de produtos com polpa e fibra, $67 \%$ disseram que já haviam consumido preparados em pó para refresco com adição de polpa, mas apenas 33\%, o produto com adição de fibra.
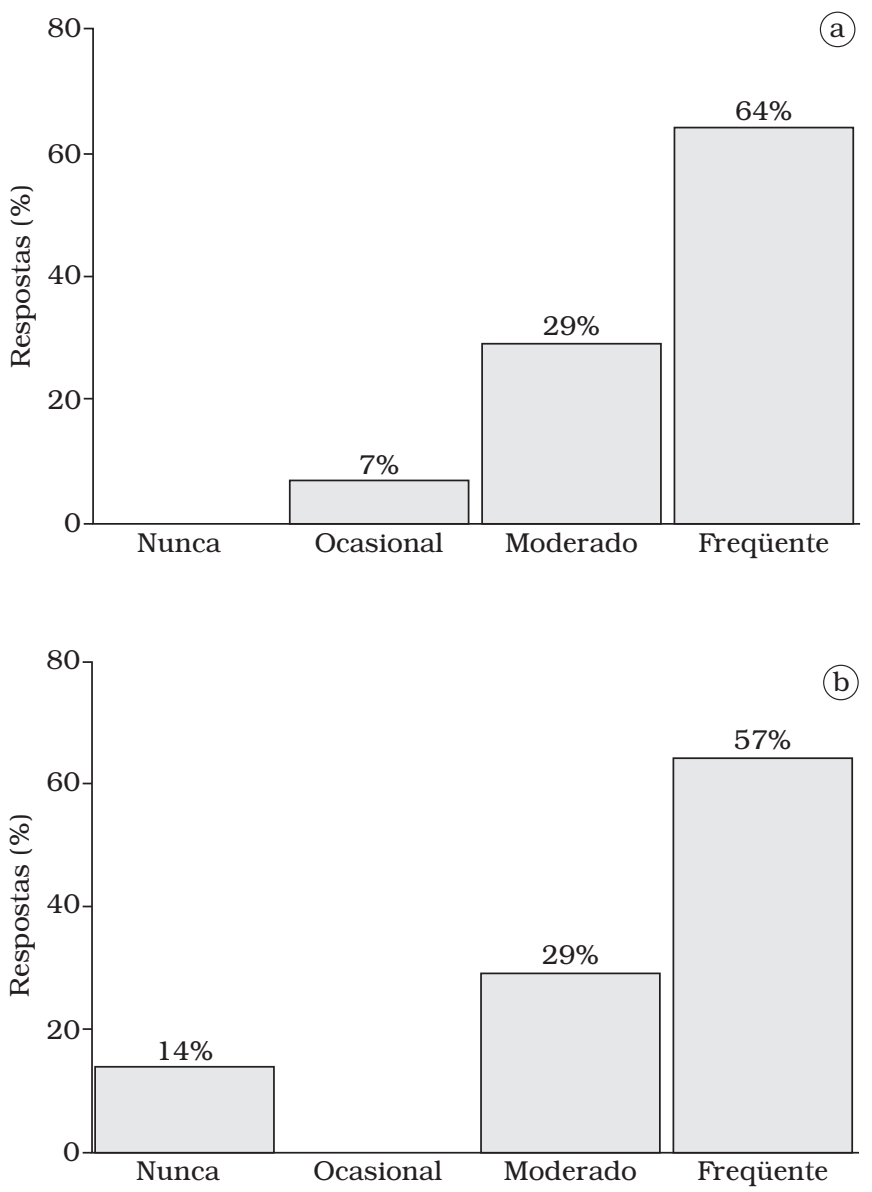

Figura 2. Freqüência de consumo de refrescos em geral (a) e de preparados em pó para refresco (b) dos provadores do teste descritivo; Ocasional: algumas vezes por ano; Moderado: algumas vezes por mês; Freqüente: algumas vezes na semana.
Levantamento de atributos e avaliação do desempenho dos provadores

Os provadores levantaram termos diferenciados para a caracterização da aparência, aroma, sabor e textura das amostras. Os atributos variaram em número, de 5 a 11, com média de 7 por provador (Anexo 1).

O comportamento da equipe de 14 provadores foi analisado empregando-se as duas primeiras dimensões, responsáveis por uma explicação de 33\% da variabilidade (Tabela 2).

Tabela 2. Porcentagem de explicação da solução bidimensional dos 14 provadores do teste descritivo.

\begin{tabular}{cccc}
\hline \multirow{2}{*}{ Dimensão } & \multicolumn{3}{c}{ Explicação (\%) } \\
\cline { 2 - 4 } & Consenso & Resíduo & Total \\
\hline 1 & 24 & 17 & 41 \\
2 & 9 & 7 & 16 \\
\hline
\end{tabular}

No gráfico de consenso (Figura 3), os produtos são representados por triângulos, que indicam a repetibilidade das amostras (quanto maior a distância entre os vértices dos triângulos, menor repetibilidade).

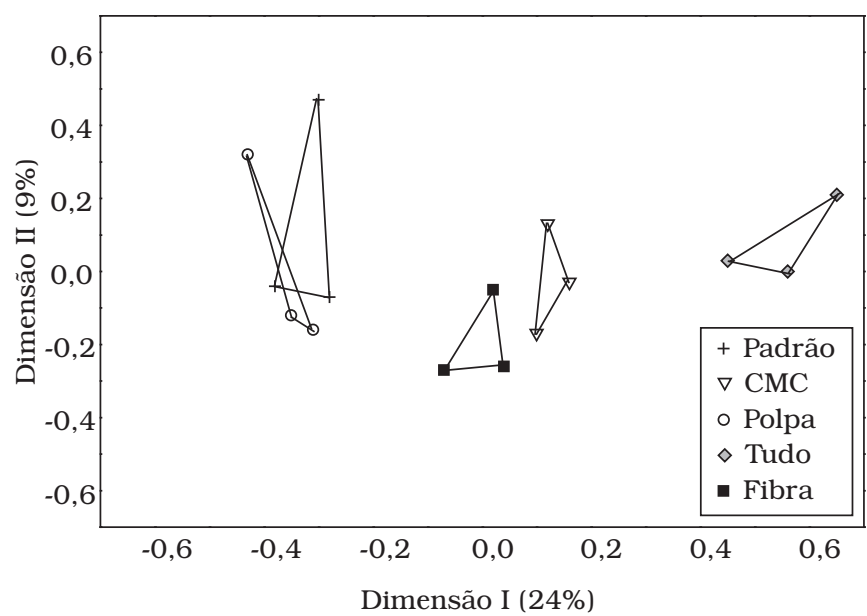

Figura 3. Configuração de consenso das amostras.

Foram consideradas a configuração geral dos provadores (Figura 4), as porcentagens de variância residual (Figura 5) e a configuração das amostras para cada provador, para avaliar a repetibilidade e o poder de discriminação da equipe.

No geral, a configuração da equipe mostrou um comportamento pouco diferenciado, somente o provador 2 apresentou-se mais afastado do grupo, indicando uma possível discordância (Figura 4).

Com relação à variância residual, as maiores porcentagens $(2,6 ; 2,7$ e $2,8 \%)$ foram observadas para os provadores 3,9 e 12, respectivamente (Figura 5), havendo pouca diferença de comportamento entre os provadores da equipe. 


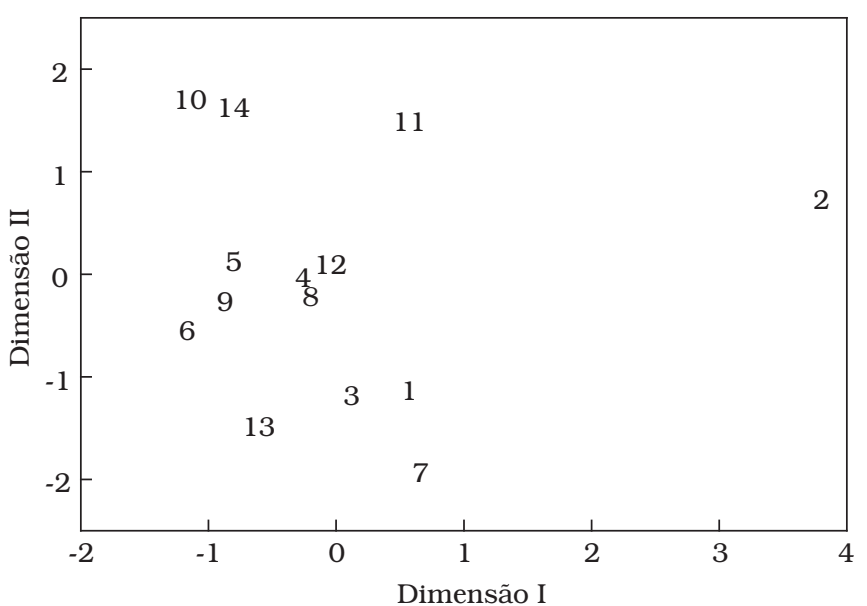

Figura 4. Configuração geral dos provadores.

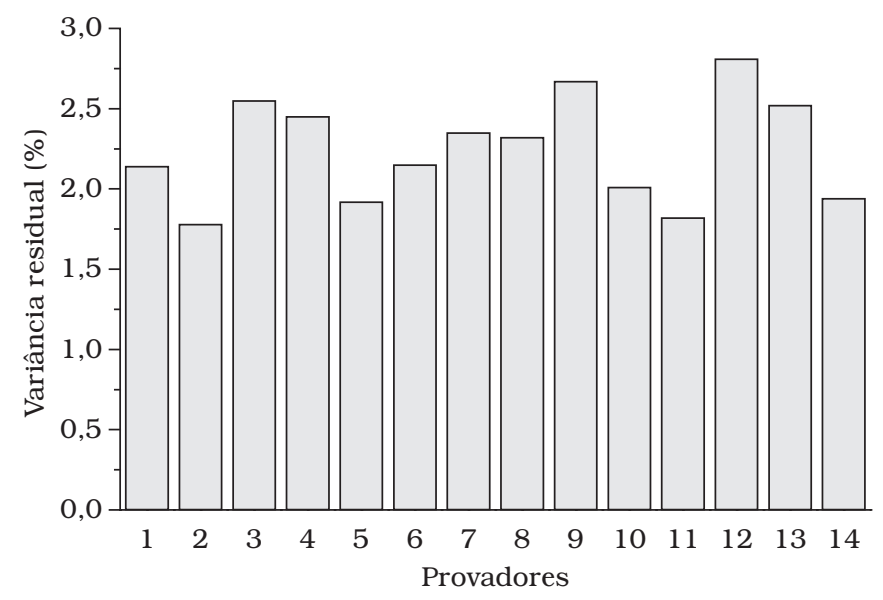

Figura 5. Distribuição da variância residual dos provadores.

Considerando a configuração da equipe e as porcentagens de variância residual, haveria a possibilidade dos provadores 2 , 3, 9 e 12 estarem dificultando o consenso. Analisaram-se, então, as configurações individuais que forneciam mais informações sobre a repetibilidade do provador, sua capacidade de discriminar as amostras, bem como observar o quanto a percepção diferia do consenso (Figura 3). Observou-se que, no geral, apesar de apresentarem pior repetibilidade em relação ao grupo, esses provadores conseguiam discriminar os produtos, e a configuração individual das amostras era próxima do consenso. Além disso, quando foi reaplicada a Análise Procrustes Generalizada desconsiderando-se o resultado desses provadores, não se observou diferença na variância explicada e na configuração de consenso, optando-se assim por manter os resultados de todos os provadores da equipe.

\section{Análise das amostras}

Na configuração de consenso para as amostras (Figura 3), utilizando-se os atributos de aparência, aroma, sabor e textura, a primeira dimensão foi responsável por $24 \%$ de explicação e a segunda dimensão explicou $9 \%$ da variabilidade (Tabela 2).

Observou-se que as amostras foram bem discriminadas apesar do total de variância explicada não ser alto (33\%). Na técnica do Perfil Livre, no geral os provadores diferem mais em seus julgamentos em relação à análise descritiva convencional por não terem sido treinados, resultando numa menor variabilidade explicada ${ }^{19}$.

Apesar da técnica estatística permitir eliminar as variações devidas a diferentes interpretações dos termos descritivos, não havendo necessidade que o provador utilizasse um vocabulário comum na caracterização dos atributos, observou-se que as definições para os atributos eram bastante parecidas.

A dimensão 1 foi a mais importante na discriminação, sendo explicada na direção positiva por atributos de sabor (sabor doce), aparência (cor, turbidez, opacidade e presença de partículas) e textura (consistência, encorpado, viscosidade e grumoso) e, na direção negativa pelo atributo sabor ácido (Tabela 3).

A amostra padrão e a amostra formulada com polpa foram consideradas pelos provadores como apresentando menor intensidade de cor laranja e turbidez e como sendo menos consistentes ou encorpadas e mais ácidas. A amostra com todos os ingredientes foi considerada como apresentando características opostas: maior intensidade de cor laranja e turbidez, mais encorpada e menos ácida. Foram ainda citados outros atributos de aroma e sabor pelos provadores $(1,2,5,8,11,12)$, mas suas utilizações não foram consistentes (Figura 3).

A dimensão 2, menos importante na caracterização das amostras, foi correlacionada com atributos de aroma e sabor associados a características de laranja: aroma de suco de laranja, adocicado e de laranja e sabor de laranja e doce. As amostras formuladas com fibra e CMC foram caracterizadas como amostras de maior aroma de laranja, sabor laranja e sabor e aroma doce. Em comentários feitos pelos provadores no teste de aceitação (item 4.3.2), relatou-se que essas amostras apresentavam sabor e aroma mais intenso de laranja e doce (Tabela 3 e Figura 3).

Em um trabalho realizado por JAIME et al. ${ }^{11}$, no qual se estudou a interação entre as sensações de textura e compostos voláteis, utilizando-se de sobremesas de gelatina como um sistema-modelo, os dois primeiros eixos principais separaram as amostras pelos atributos de sabor e aroma característicos da fruta.

As duas primeiras dimensões importantes na caracterização das amostras estiveram correlacionadas com o sabor característico da fruta em um trabalho sobre bebidas de groselha realizado por PIGGOTT et al. ${ }^{21}$.

Uma vez que no teste descritivo observou-se que a amostra com polpa não se diferenciava da amostra padrão, mas verificou-se diferenças entre as outras formulações, optou-se, então, por caracterizar através de parâmetros físico-químicos e aceitação, o impacto da adição individual de CMC e goma acácia. 
Tabela 3. Atributos que apresentaram maiores correlações nas duas primeiras dimensões para cada provador.

\begin{tabular}{|c|c|c|}
\hline Provador & Dimensão $1^{*}$ & Dimensão $2^{*}$ \\
\hline 1 & Aroma de laranja $(-0,62)$; Sabor doce $(0,61)$ & Presença de grânulos $(-0,54)$; Sabor laranja $(-0,49)$ \\
\hline 2 & Cor $(-0,54)$; Sabor doce $(0,63)$; Sabor ácido $(-0,52)$ & $\begin{array}{l}\text { Transparência }(-0,44) \text {; Brilho }(-0,44) \text {; } \\
\text { Aroma laranja artificial }(-0,29)\end{array}$ \\
\hline 3 & Cor $(0,57)$; Presença de partículas $(0,81)$; Consistência $(0,88)$ & Aroma suco de laranja $(-0,32)$; Sabor doce $(-0,85)$ \\
\hline 4 & $\begin{array}{l}\text { Turbidez (aparência) }(0,78) \text {; Viscosidade }(0,59) \text {; } \\
\text { Pedaços de fruta }(0,58)\end{array}$ & Cor $(0,7)$; Aroma ácido $(-0,21)$ \\
\hline 5 & $\begin{array}{l}\text { Cor }(0,63) \text {; Sabor laranja artificial }(0,6) \text {; Sabor doce }(0,49) \text {; } \\
\text { Consistência }(0,71)\end{array}$ & Transparência $(0,33)$; Aparência suco natural $(0,24)$ \\
\hline 6 & $\begin{array}{l}\text { Cor alaranjada }(0,56) \text {; Viscosidade }(0,61) \text {; Turbidez }(0,72) \text {; } \\
\text { Sabor doce }(0,48)\end{array}$ & $\begin{array}{l}\text { Cor alaranjado }(-0,51) \text {; Aroma adocicado }(-0,57) \text {; } \\
\text { Aroma laranja artificial }(-0,36)\end{array}$ \\
\hline 7 & $\begin{array}{l}\text { Encorpado (aparência) }(0,83) \text {; Sabor adocicado }(0,65) \text {; } \\
\text { Encorpado (textura) }(0,72)\end{array}$ & $\begin{array}{l}\text { Cor }(-0,5) \text {; Aroma de suco de laranja }(-0,62) \text {; } \\
\text { Sabor adocicado }(-0,33)\end{array}$ \\
\hline 8 & Sabor doce $(0,49)$; Viscosidade $(0,39)$; Sabor laranja $(0,4)$ & Aroma de laranja $(-0,47)$ \\
\hline 9 & Sabor doce $(0,73)$; Sabor ácido $(-0,7)$; Suavidade $(0,69)$ & $\begin{array}{l}\text { Cor }(-0,63) \text {; Sabor laranja }(0,52) \text {; Transparência }(-0,8) \text {; } \\
\text { Aroma de laranja }(0,56)\end{array}$ \\
\hline 10 & $\begin{array}{l}\text { Opacidade }(0,59) \text {; Grumoso }(0,66) \text {; Sabor ácido }(-0,63) \text {; } \\
\text { Encorpado }(0,63)\end{array}$ & Cor $(-0,41)$; Aroma de laranja $(0,44)$; Grumoso $(0,39)$ \\
\hline 11 & $\begin{array}{l}\text { Cor }(0,4) \text {; Sabor adstringente }(-0,36) \text {; } \\
\text { Partículas em suspensão (aparência) }(-0,34) \text {; } \\
\text { Sabor suco de laranja }(0,3)\end{array}$ & $\begin{array}{l}\text { Aroma suco de laranja }(-0,61) \text {; Sabor suco de laranja } \\
(-0,38) \text {; } \\
\text { Sabor doce }(-0,3)\end{array}$ \\
\hline 12 & $\begin{array}{l}\text { Translúcido }(-0,69) \text {; Aroma laranja natural }(0,72) \text {; } \\
\text { Aroma laranja artificial }(-0,72) \text {; Sabor doce }(0,46) \text {; } \\
\text { Adstringência (textura) }(-0,76)\end{array}$ & Cor alaranjada $(-0,64) ;$ Translúcido $(-0,4)$ \\
\hline 13 & Homogeneidade $(-0,58)$ & Aroma de laranja $(-0,32) ;$ Sabor laranja $(-0,44)$ \\
\hline 14 & Cor $(0,42)$; Consistência $(0,79)$; Sabor ácido $(-0,69)$ & Aroma de laranja $(-0,7)$; Sabor doce $(-0,29)$ \\
\hline
\end{tabular}

*Valores entre parênteses indicam correlações com cada dimensão.

\subsection{Caracterização físico-química e da aceitabilidade}

\section{Caracterização da equipe do teste afetivo}

Participaram da análise de aceitação 58 homens e 60 mulheres. A metade era composta por alunos de graduação e pósgraduação e a outra metade por funcionários e professores da universidade e da empresa DORI (42\%). A maioria dos provadores era jovem ( $80 \%$ na faixa até 35 anos) e apresentava nível de escolaridade diferenciada: $9 \%$ havia concluído o $1^{\circ}$ grau, $60 \%$ o $2^{\circ}$ grau, e $31 \%$ possuía nível igual ou superior ao $3^{\circ}$ grau.

Os participantes (118 provadores) relataram gostar de refresco de fruta e do sabor laranja (99\%). Quanto à familiaridade com o produto, observou-se comportamento semelhante ao da equipe empregada na análise descritiva (Figura 2). Com relação à freqüência de consumo de refrescos em geral, 10\% relataram consumir ocasionalmente (algumas vezes ao ano), 25\% moderadamente (algumas vezes ao mês) e 65\% freqüentemente (algumas vezes por semana). Com respeito aos preparados em pó comerciais, $3 \%$ dos provadores relataram nunca consumir, $17 \%$ consumiam ocasionalmente, $25 \%$ moderadamente, e $55 \%$ freqüentemente.

Os provadores da equipe de aceitação eram mais conservadores com relação à escolha dos produtos: do total de participantes 53\% costumam comprar sempre o mesmo sabor e/ou marca e apenas $47 \%$ relataram já ter consumido preparados em pó com adição de polpa ou fibra.

\section{Caracterização físico-química e avaliação da aceitação}

Os produtos apresentaram teor de vitamina C entre 7,2 e 7,5 mg. $100 \mathrm{~mL}^{-1}$. SILVA et al. ${ }^{23}$ trabalhando com 11 amostras de refrescos comerciais encontraram variação de 0,67 a $32 \mathrm{mg} .1100 \mathrm{~g}^{-1}$.

A adição de CMC aumentou o teor de sólidos solúveis e acidez titulável, mas o "ratio" não apresentou variação ficando na faixa de 9,2 a 9,8. Com relação ao $\mathrm{pH}$, a amostra com goma acácia apresentou o maior valor $(2,79)$ (Tabela 4), mas dentro da faixa de valores de produtos comerciais $(2,43,1)^{23}$.

As maiores alterações foram observadas nos parâmetros de cor e turbidez. A adição de CMC e goma acácia aumentou a intensidade de cor laranja, mas o efeito mais pronunciado foi na turbidez, duplicando os valores observados para o padrão (Tabela 4).

Com relação ao teste sensorial afetivo, a amostra padrão foi menos aceita (nota média 5,8) que as amostras formuladas com CMC e Fibra (6,5 e 6,7, respectivamente). As amostras com CMC e Fibra apresentaram uma maior porcentagem de aprovação (77\%); metade do índice de rejeição (em torno de $10 \%$ ) em relação à amostra padrão (58\% de aprovação e $23 \%$ de rejeição) (Tabela 5).

$\mathrm{O}$ atributo citado como o mais apreciado, em relação às amostras formuladas com Fibra e CMC, foi o sabor (Tabela 6). Nas observações, os provadores comentaram que nestes formulados o sabor característico de laranja era mais intenso. Para essas gomas, é descrito na literatura o emprego como fixadores de flavor, e a goma acácia se destaca por reduzir a 
Tabela 4. Valores dos parâmetros físico-químicos para os formulados de refresco de laranja ${ }^{1,2}$.

\begin{tabular}{cccccc}
\hline Marca & $\mathrm{pH}$ & $\begin{array}{c}\text { Acidez titulável } \\
\left(\mathrm{g} \cdot \mathrm{mL}^{-1}\right)\end{array}$ & $\begin{array}{c}\text { Sólidos solúveis } \\
\left({ }^{\circ} \text { Brix }\right)\end{array}$ & Cor laranja (UA) $^{*}$ & ${\text { Turbidez }(\mathrm{UA})^{* *}}^{\mathrm{a}}$ \\
\hline Padrão & $2,57 \pm 0,00^{\mathrm{b}}$ & $0,22 \pm 0,03^{\mathrm{ab}}$ & $2,07 \pm 0,00^{\mathrm{b}}$ & $0,95 \pm 0,03^{\mathrm{c}}$ & $0,25 \pm 0,01^{\mathrm{c}}$ \\
CMC & $2,59 \pm 0,06^{\mathrm{b}}$ & $0,23 \pm 0,03^{\mathrm{a}}$ & $2,15 \pm 0,00^{\mathrm{a}}$ & $1,18 \pm 0,03^{\mathrm{a}}$ & $0,52 \pm 0,03^{\mathrm{b}}$ \\
Fibra & $2,79 \pm 0,01^{\mathrm{a}}$ & $0,21 \pm 0,00^{\mathrm{b}}$ & $2,07 \pm 0,01^{\mathrm{b}}$ & $1,00 \pm 0,01^{\mathrm{b}}$ & $0,55 \pm 0,03^{\mathrm{a}}$ \\
\hline
\end{tabular}

${ }^{1}$ Média de duas análises \pm desvio padrão; ${ }^{2}$ Letras diferentes na mesma linha indicam diferença significativa ( $\left.\mathrm{p} \leq 0,05\right)$; ${ }^{*}$ Diferença entre absorvância a 450 nm e 600 nm; e **Absorvância a $600 \mathrm{~nm}$.

Tabela 5. Nota média de aceitação e porcentagens de aprovação, indiferença e rejeição dos formulados.

\begin{tabular}{lcccc}
\hline Amostra & Nota & Aprovação (\%) & Indiferença (\%) & Rejeição (\%) \\
\hline Fibra & $6,7^{\mathrm{a}}$ & 77 & 11 & 12 \\
CMC & $6,5^{\mathrm{a}}$ & 77 & 13 & 10 \\
Padrão & $5,8^{\mathrm{b}}$ & 58 & 19 & 23 \\
\hline
\end{tabular}

*Média de 118 provadores, letras diferentes na mesma coluna indicam diferença significativa $(\mathrm{p} \leq 0,05)$; Aprovação $(\%)=$ porcentagem de notas de 6 a 9 ; Indiferença $(\%)=$ porcentagem de notas 5; e Rejeição $(\%)=$ porcentagem de notas de 1 a 4 .

tensão superficial ${ }^{9}$. Os parâmetros físico-químicos demonstraram que a amostra formulada com CMC apresentou uma maior acidez titulável e ${ }^{\circ}$ Brix em relação à amostra padrão, sendo que a formulada com fibra obteve um $\mathrm{pH}$ mais alto. Na análise descritiva, as amostras com CMC e fibra foram descritas como mais "características" (maior aroma de laranja, sabor laranja e sabor e aroma doce), menos ácidas e apresentando maior intensidade de cor laranja e turbidez.

Tabela 6. Características sensoriais mais apreciadas e menos apreciadas citadas pelos provadores em relação às amostras padrão, CMC e fibra.

\begin{tabular}{ccrlc}
\hline Formulado & $\begin{array}{c}\text { Características } \\
\text { mais } \\
\text { apreciadas }\end{array}$ & $\begin{array}{c}\text { Resposta } \\
(\%)\end{array}$ & $\begin{array}{c}\text { Características } \\
\text { menos } \\
\text { apreciadas }\end{array}$ & $\begin{array}{c}\text { Resposta } \\
(\%)\end{array}$ \\
\hline Fibra & Sabor & 54 & Doçura & 39 \\
& Doçura & 15 & Sabor & 19 \\
& Aroma & 12 & Gosto residual & 17 \\
CMC & Sabor & 49 & Doçura & 22 \\
& Doçura & 22 & Sabor & 28 \\
& Aroma & 8 & Aroma & 11 \\
Padrão & Sabor & 47 & Adstringência & 21 \\
& Doçura & 19 & Acidez & 17 \\
& Aroma & 11 & Sabor & 16 \\
\hline
\end{tabular}

Com relação à amostra de menor média de aceitabilidade (Padrão), os provadores citaram como principal causa de rejeição a adstringência (Tabela 6). Apesar da maior diferença entre as amostras ter sido observada para a intensidade de cor laranja e turbidez, e desses parâmetros terem sido importantes para discriminação na análise descritiva, a aparência não foi citada como característica importante para preferência.

\section{Conclusões}

Através da metodologia descritiva de Perfil Livre as amostras foram caracterizadas e separadas com base em atributos de aparência (cor e turbidez), aroma (adocicado e de laranja), sabor (doce, de laranja e ácido) e textura (viscosidade e grumoso). O padrão e a amostra formulada com polpa, que não foram diferenciadas sensorialmente, apresentaram menor intensidade de cor laranja e turbidez e foram consideradas menos encorpadas e mais ácidas que os outros refrescos. As formulações com CMC e fibra se diferenciaram do padrão e apresentaram comportamento intermediário. A formulação com todos os ingredientes apresentou características opostas: maior intensidade de cor e turbidez, mais encorpada e menos ácida. As amostras formuladas com CMC e fibra foram mais aceitas que o padrão.

\section{Agradecimentos}

À CAPES pela concessão de Bolsa de Mestrado à Valentina de Fátima Caleguer e à CNI Colloides Naturels pela goma acácia e pela disponibilidade no atendimento e informações.

\section{Referências bibliográficas}

1. AOAC - Association of Official Analytical Chemists. Official methods of analysis. Washington, D.C., 1995. p. 16-17.

2. BENASSI, M. T.; ANTUNES, A. J. A comparison of methaphosphoric and oxalic acids as extractants solutions for the determination of vitamin $\mathrm{C}$ in selected vegetables. Arquivos de Biologia e Tecnologia, Curitiba, v. 31, n. 4, p. 507-513, 1988.

3. BRASIL. Ministério da Saúde. Decreto no 2314 da Agencia Nacional de Vigilância Sanitária, de 04 de setembro de 1997. Regulamenta a Lei $\mathrm{n}^{\circ} 8.918$, de 14 de julho de 1994, que dispõe sobre a padronização, a classificação, o registro, a inspeção, a produção e a fiscalização de bebidas. Disponível em: http://elegis.anvisa.gov.br/leisref/public/home.php. Acesso em: 20 mar. 2007.

4. CALEGUER, V. F.; TOFFOLI, E. C., BENASSI, M. T. Avaliação da aceitação de preparados sólidos comerciais para refresco sabor laranja e correlação com parâmetros físico-químicos. Semina. Ciências Agrárias, Londrina, v. 27, n. 4, p. 605-611, 2006.

5. CECCHI, H. M. Fundamentos Teóricos e práticos em análise de alimentos, 2. ed. Campinas: Livraria da Unicamp. 1999. p. 119-123.

6. CNI Colloides Naturels International (suzan@cnbrasil.com.br). Comunicação eletrônica pessoal. Informações FIBREGUM. E - mail to Marta de Toledo Benassi (martatb@uel.br). 30 abril 2004.

7. ESTADÃO. Refresco em pó ganha cara e conceitos novos (07 de abril de 2002). Disponível em: http://www.estado.estadão.com. br/editoriais/2002/04107/eco 023.html. Acesso: 10 mar. 2006.

8. FUJII, F. O plus do sabor - A adição de polpa revigora a disputa dos fabricantes de refrescos em pó. Doce Revista, São Paulo: Editora Definição. n. 82, p. 32-33, 36, 38, 40, 42-44, 46-48, 50, 1999. 
9. GLICKSMANN, M. Food Hydrocolloids. London: Academic Press. 1986. v. 2, p. 7-47.

10. INSTITUTO ADOLFO LUTZ Normas Analíticas do Instituto Adolfo Lutz - Métodos químicos e físicos para análise de alimentos. São Paulo: Inst. Adolfo Lutz, 1976. v. 1, p. 23-24 e 138-141.

11. JAIME, I.; MELA, D. J.; BRATCHELL, N. A study of texture-flavor interations using Free-Choice Profiling. Journal of Sensory Studies, Trumbull, v. 8, n. 3, p. 177-188, 1993.

12. KYRIAKIDIS, N. B. Use of pectinesterase for detection of hydrocolloids addition in natural orange juice. Food Hydrocolloids, New York, v. 19, n. 6, p. 497-500, 1999.

13. MITCHEL, H. Bebidas Enriquecidas com Fibras. Ingredientes, São Paulo, v. 20, n. 1, p. 72-75, 2004.

14. MOSKOWITZ, H. R. Product testing and sensory evaluation of foods - Marketing and R \& D Aproaches. Food and Nutrition Press, Inc. Westport, 1983. p. 605.

15. MUÑOZ, A. M.; CIVILLE, G. V.; CARR, B. T. Sensory evaluation in quality control. New York: Van Nostrand Reeinhold, 1992. $240 \mathrm{p}$.

16. MURRAY, J. M.; DELAHUNTY, C. M.; BAXTER, I. A. Descriptive sensory analysis; past, present and future. Food Research International, Oxford, v. 34, n. 6, p. 461-471, 2001.

17. NOVIANT Noviant group (johan.vandekoppel@noviantgroup. com). Comunicação eletrônica pessoal. CMC gum information. E-mail to Marta de Toledo Benassi (martatb@uel.br). 24 jun 2004.
18. NOVIANT Cekol cellulose gum for food applications. Disponível em: http:// www.noviant group.com/en/a_food.html Acesso: 20 mar. 2007.

19. OLIVEIRA, A. P. V.; BENASSI, M. T. Perfil Livre : uma opção para Análise Sensorial Descritíva. Boletim da SBCTA, Campinas, v. 37, n. supl., p. 66-72, 2003.

20. OP \& P. PRODUCT RESEARCH, Senstools versão 2.3. Utrecht; OP \& P. Product Research, 1995 - 1998. Conjunto de programas $1 \mathrm{CD}$ room

21. PIGGOTT, J. R.; PATERSON, A.; CLYNE, J. Prediction of flavor intensity of blackcurrant (Ribes nigrum L.) drinks from compoditional data on fruit concentrates by partial least squares regression. International Journal of Food Science and Tecnology, Oxford, v. 28, n. 6, p. 629-637, 1993.

22. REVISTA UPDATE Prático e barato (abril de 2002). Câmara Americana de Comércio. Disponível em: http://www.revistaupdate. com.br/revista/revista2002-03-20a/materia2002-03-21f/ pagina2002-03-21g/index_conteudo. Acesso: 20 mar. 2007.

23. SILVA, P. T. et al. Sucos de laranja industrializados e preparados sólidos para refrescos: estabilidade química e físico-química. Ciência e Tecnologia de Alimentos, Campinas, v. 25, n. 3, p. 597-602, 2005.

24. STATSOFT. STATISTICA for Window - Computer programa manual. Versão 6.0 Tulsa: Statsoft Inc. 2001.

25. THEBAUDIN, J. Y. et al. Dietary fibres: Nutritional and Technological interest. Trends in Food Science \& Technology, Cambridge, v. 8, n. 2, p. 41-47, 1997. 